\title{
HIV/AIDS Risk and Prevention Issues Among Inuit Living in Nunavut Territory of Canada
}

\author{
ALEXANDER KUMAR \\ Department of Infection, Immunity and Inflammation, University of Leicester, Leicester, U.K.
}

\begin{abstract}
Aim: HIV infections occur across the Arctic but their incidence among aboriginal populations varies vastly. At the time this research was initiated there were no data on their occurrence, risk of HIVIAIDS or preventive strategies among Inuit living in the Nunavut territory of Canada. This review is the first to assess the risk of HIV infection among Inuit and evaluate current prevention strategies among Canadian-Inuit populations. Materials and Methods: The contents of this article are based on the author's own research, undertaken during 3 visits to the Canadian Arctic and the published literature. Results: Disproportionately high rates of Chlamydia and Gonorrhoea within Inuit communities confirm the potential threat of silent HIV transmission. Inuit awareness of HIVIAIDS issues remains inadequate. It is easy to blame distorted perceptions fuelled by the media, religious influence and sociocultural factors. Aboriginal and Inuit groups, including youth, women and injection drug abusers are at increased risk of infection. The adaptability of proven prevention methods including condom use and male circumcision are discussed. Access to treatment, adherence and resistance issues in the North Canada, require attention. Conclusion: HIVIAIDS poses a considerable threat to Canadian Inuit public health. The most important problem to be addressed is Inuit lack of awareness and understanding of HIV. Education is the single most effective means of prevention. Inuit-specific and culture-
\end{abstract}

Abbreviations: AIDS, Acquired autoimmune deficiency syndrome; HIV, human immunodeficiency virus; STI, sexually transmitted infection; IVDU, intravenous drug users; MTCT, mother to child transmission; MC, male circumcision; NEPC, needle exchange programme; DOT, direct observation therapy; ART, antiretroviral therapy; VCT, voluntary counselling and testing; MSM, men who have sex with men.

Correspondence to: Dr. Alexander Kumar, NIHR Academic Fellow Infectious Diseases, Department of Infection and Tropical Medicine, University Hospitals of Leicester NHS Trust, Leicester UK. Email: dralexanderkumar@gmail.com

Key Words: Inuit, Aboriginals, HIV/AIDS, sexually transmitted disease, epidemiology, review. sensitive interventions are recommended. Further research opportunities exist to investigate Inuit understanding over HIVIAIDS issues and to assess local prevention efforts.

The Human Immunodeficiency Virus causes Acquired Immunodeficiency Syndrome. Although there exist treatments available for AIDS, there is no cure and it is a fatal disease (1-5). Over the past 3 decades the global HIV epidemic has become a human, economic and cultural catastrophe with over 20 million deaths (6-9). There is a growing concern for the Canadian Aboriginal population, which includes registered and non-registered Indians, Métis and Inuit (Eskimo), who remain at increased risk of HIV infection. The volume of research conducted on Canadian Aboriginal populations differs enormously and there has not yet been a review of the information available on Inuit HIV/AIDS. Inuit live within four distinct regions of Canada and face similar health challenges. The percentage of total Canadian Inuit in 4 regions: Nunavut Territory, Nunavik, Nunatsiavut and Inuvialuit respectively are 50\% 21\%, 10\% and 9\% (10-13). The present review focused on Inuit living in Nunavut and evaluates strategies and tools for HIV/AIDS prevention.

There is a lack of data on the extent of HIV/AIDS among Inuit $(8,14)$. Therefore this study was undertaken to fulfil this glaring void (15). The availability of such as information is necessary for disease prevention and initiation of therapeutic measures $(16,17)$. The questions to be considered are (i) what factors increase the risk of acquiring HIV among Inuit? (ii) What global and local prevention methods exist? (iii) How applicable and effective would these methods be among Inuit?

\section{Patients and Methods}

\section{Sources of Data}

In order to familiarize myself and gain insight into the subject of this article, I spent 4 months in Iqualuit and Churchill. I attended patient clinics in hospitals and with ethics approval from the Nunavuit Research Institute collected information on sexually transmitted infections (STI). Apart from discussion with the hospital staff, I met 
Inuit and elders to learn their perceptions, views, understanding, reservations about the problems and strategies for future progress. Articles in the English language only, were selected from initial literature searches of Medline, PubMed, AIDSline and Web of Science databases and Google Scholar, using the terms: HIV; Inuit; and Canada. A wider search was then completed from different combinations including alternative terms: Arctic; Aboriginal; Eskimo; and AIDS since limited studies were found in the initial search. Other articles were chosen from references quoted in previously selected articles. Further searches were conducted using the specific terms: Inuit health behaviour; Antiretroviral Drugs; Treatment; Prevention; Voluntary Counselling and Testing. Websites including World Health Organisation, Health Canada and Arctic Health Database were also searched. Although the initial focus of this literature review was on Nunavummiut communities, owing to the limited literature, some studies of Canadian aboriginal populations in rural and urban contexts were also included.

\section{Inuit Health}

Arctic health specialists, including Bjerregaard and Young (18-20), have highlighted and quantified a Canadian-Inuit health disparity experienced by Nunavut Inuit, is shown in Table I.

Nunavut's Chlamydia and Gonorrhoea rates are 20-times the national average, being highest among local adolescents. Twenty percent of Nunavut school children have been treated for STI $(21,22)$. The risk of HIV infection is $2-5$ times higher in people with STIs (23). Therefore local Inuit are at greater risk of HIV transmission.

Aboriginal, Inuit and Nunavut Territory Infection Statistics HIV/AIDS occurs in the Arctic, in Canada, Greenland, Alaska and Russia (18, 24). The Canadian HIV/AIDS prevalence of $0.2-0.5 \%$ (1,500 HIV/AIDS-related deaths in 2003) (6), is declining with most infected patients living in Ontario, Quebec and British Colombia (25). However, Aboriginals are over-represented among Canadian HIV/AIDS cases $(12,21)$. There may also be an economic difference (26). According to the 2001 Census, Aboriginal communities comprise $3.3 \%$ of the Canadian population but $5-8 \%$ of prevalent infections (persons currently living with HIV) and 6-12\% of new HIV infections in 2002 (27). Between 1998 and 2003, the Centre for Infectious Disease Prevention and Control (CIDPC) reported 12,602 positive HIV tests. 3,706 cases included 23\% Aboriginals, registered and non-registered Indians, Métis and Inuit $(21,28)$. It is unclear how the Inuit minority is affected.

Although reliable HIV/AIDS incidence and prevalence data exist for most Canadian provinces, no concerted effort has been made to collect data in Nunavut (27). The Nunavut Comparable Health Indicators Report of 2004 reiterates,
Table I. Reasons for the health disparity experienced by Nunavut-Inuit.

Higher infant mortality rates; low birth weights

Higher rates of unintentional injuries

Lower but increasing rates of acute myocardial infarction

Poorer mental health and high suicide rates

Canada's highest tuberculosis rates

Higher rates of STIs including Chlamydia and Gonorrhoea

Higher smoking rates among youth

Lower life expectancy

Poor self-reported health

Lowest reported patient satisfaction with hospital and physician care

"Because there have been no new diagnoses of HIV infection for the past seven years, no trend can be seen in this territory" (25).

It is believed that undiagnosed cases exist in Nunavut and the chance to prevent a potential disaster may have been missed. Proposed explanations include that HIV-positive cases can remain asymptomatic for years and testing coverage is poor in Nunavut. However, the territory's only hospital in Iqaluit has a reliable uptake in testing all pregnant females regularly referred from all communities within the territory. Since the health of local pregnant women is not a reliable representation of local public health, this explanation may be invalid. Despite the high prevalence of STIs, HIV/AIDS does not seem to be present among Inuit in the epic proportions once feared. The rarity of haemophilia, surgical operations, blood transfusions and homosexual activity among Inuit populations may have limited the spread of HIV $(18,26)$. It is more likely that geographical isolation has contributed to the low rates reported.

\section{Prevention of HIV Infection in Canada and Nunavut}

All Canadians including Inuit regardless of their location are entitled to free health care via the Canada Health Act. In Nunavut, a territorial government with fractured jurisdictional responsibilities distributes skeleton health care via the Canada Health Act $(29,30)$. Community health nurses provide primary health care services via a health centre located in each community. Nunavut has Canada's highest health care costs, spending a fifth of its health budget on medical travel using outside specialist services. Isolation and extreme climatic conditions remain principal obstacles, despite enticing wages (31). The government has greater responsibility and accountability for the health of Inuit through the Non-Insured Health Benefits (NIHB) Programme. NIHB of Health Canada provides all costs for certain medical, dental and pharmacy services to eligible 


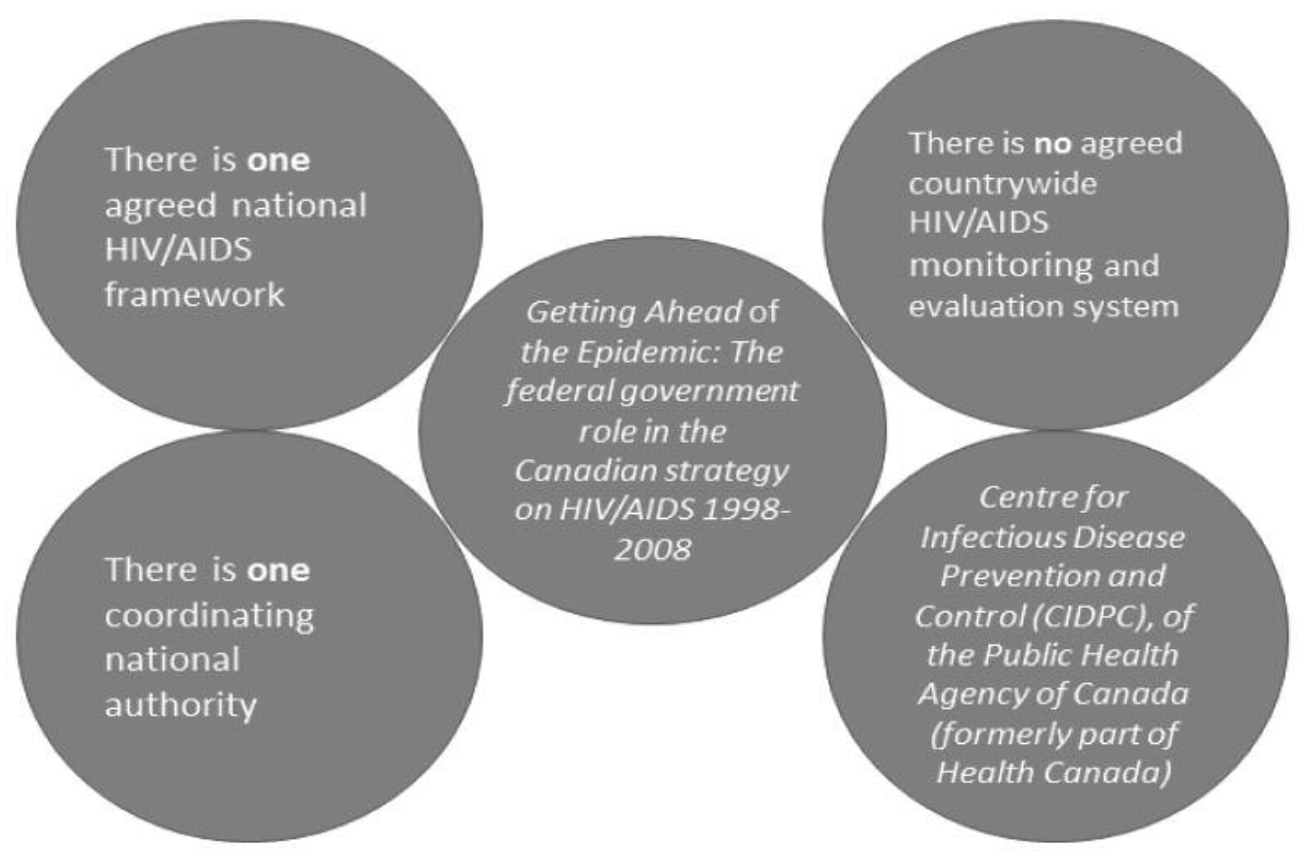

Figure 1. Gaps in Information Regarding the Extent of HIV/AIDS Among Inuit.

Land Claims Beneficiary-Inuit, including medical evacuations. The aim is to help Inuit attain equal health status with other Canadians, by maintaining and managing health and preventing disease, using individualized costeffective interventions $(32,33)$.

\section{Canadian National AIDS Prevention Programme}

The quality of Canada's fully implemented surveillance system is good (34). However, the federal government has had a limited role. Independent recommendations in 2003 to double HIV/AIDS funding, increase federal involvement and designate funding for Inuit, have not been implemented (35). In high-income countries such as Canada, treatment has been a higher priority than prevention, allowing increased HIV transmission (7) (Figure 1).

\section{HIV Prevention in Nunavut}

Independent organisations in Nunavut, promoting HIV/AIDS awareness such as the Pauktuutit Women's Association (including the Canadian Inuit HIV/AIDS Network) and Canadian Aboriginal Aids Network, have produced useful advertisements and education booklets in Inuktitut and English. The impact is unknown. Inuit-specific projects and programmes are being slowly implemented. 'Health is a Community Affair' was a successful door-to-door health awareness and promotion strategy, in the North-western Territories in the 1980s. It broke cultural taboos and language diversity issues by converting materials on HIV/AIDS into the local cultural and lingual context, using radio messages and posters. The campaign was wellreceived, promoting HIV/AIDS awareness (36). However, Inuit awareness of HIV/AIDS issues remains below even other Aboriginal populations. The current absence of Territory-wide education and prevention initiatives further increases Inuit risk (37).

\section{Understanding HIV/AIDS Among Aboriginals and the Inuit}

Impact of HIV/AIDS. The effects of HIV/AIDS on Aboriginal people remain largely unacknowledged (38). Harrison states, "The question remains as to whether there is an undiagnosed iceberg or unidentified iceberg of disease" (39). HIV/AIDS has affected different Aboriginal groups with significant impact on women and even children (21). This has led to the social exclusion of HIV-positive Inuit children because of others' misconceptions (40). An urbanbased study indicated increased suicide risk among HIVpositive males (41). Whilst one source states that unprotected heterosexual sex remains the primary pathway of Inuit HIV infection, others identify Intra-Venous Drug Users (IVDUs) as a greater infection risk $(21,42)$. Differences in HIV 
transmission modes are reported between Aboriginal men and women. Four Aboriginal risk groups are identified: Women, IVDUs, Youth, Men who have Sex with Men (MSM). In the male 'at-risk groups' $45.6 \%$ were MSM, $29.3 \%$ IVDU and $10.9 \%$ heterosexuals. Among women however, $65 \%$ were IVDU and 32\% heterosexuals. Such evidence wrongly suggests that IVDU accounts for the largest proportion of HIV transmission in Aboriginal women, including Inuit (21), and highlights the importance of culture-specific research on each of the three different Aboriginal populations.

Women. In Sub-Saharan Africa more women have HIV (57\%) possibly because prostitution is common (7). It is stated, without further explanation, that Aboriginal women are significantly affected by HIV/AIDS $(21,33)$. Mckeown stated that new cases of HIV infection in Aboriginals occurred more often in women (45.3\%), but did not quote any comparable statistics. Risk factors for HIV infection among Aboriginal women remain unknown. Although sexual violence has been suggested, its role has not been understood or measured (43). Cole's survey concluded that women especially were affected by the health consequences of STIs, but did not provide any explanation, or mention HIV/AIDS (22). Incidence of HIV during pregnancy and postpartum and risk of mother-to-child transmission require further studies $(44,45)$.

Intravenous Drug Use (IVDU). Data suggest that IVDU continues to be a key mode of HIV transmission among Aboriginals. From 1998-2003, the number of HIV cases among Aboriginal IVDUs was twice the number of nonAboriginals $(21,46)$. In 2002, 53.3\% of reported Aboriginal AIDS cases and one third of Inuit cases were attributed to IVDU (21). However, it is not known whether IVDUs simply constitute a higher proportion of Aboriginals tested or whether IVDU transmission is being correctly attributed. There is no research on IVDU among Inuit populations $(47,48)$.

Youth. Young people, 15-24 years old, account for nearly half of all new HIV infections worldwide (7). Health Canada stated that Aboriginals are infected at a younger age and there has been a dramatic increase in risky behaviour among Inuit aged 20-29 years, who now account for $20.5 \%$ of all Inuit cases (21). However, Health Canada does not state its source for this information. Cole also found differences in sexual health knowledge, attitudes and behaviour, between Inuit and Non-Inuit youth in Nunavut. Her survey identified Inuit knowledge deficits and a need for better sexual education. Despite limitations that the distribution of a questionnaire and sexual education booklet were to a small and unrepresentative pocket of Inuit youth in Nunavut, these provided benefits that should be incorporated more regularly into research (22). Young (49) found smoking and STIs were common among people with a history of sexual abuse. Sexual abuse alters victims' health behaviours, increasing STI and HIV risk. A report written in a global context suggests that protecting the rights of young Inuit girls would lower HIV prevalence among the young (7).

Men who have sex with men (MSM). Inuit homosexuality is uncommon and not acknowledged within their communities. The Inuit are reported to have the lowest proportion of HIV cases, in the MSM category, among Aboriginals (21). This warrants further studies like the ones which have been carried out in Canada (50-53).

\section{The Media and HIV}

Local and community newspapers are important in disseminating health information in isolated Inuit communities, being an influential source of unmonitored disease information. The Nunatsiaq News Weekly is readily available in English and Inuktitut. Hoffman-Goetz analyzed the coverage and portrayal of HIV/AIDS risk factors in newspaper articles targeting Inuit and other Aboriginals. Major risk factors, accompanied by additional factors such as alcohol use, sexual abuse and poverty were covered in $74 \%$ of articles. Risk groups such as prostitutes, sexual abuse victims and prison inmates were identified. Heterosexual men, thought to lack HIV/AIDS knowledge, were not considered at risk. The voice of the study was largely adult male, implying that more Inuit adult males live with HIV or that they can talk more openly about it. The inaccuracy of the reporting media, a lack of adequate data to ascertain the extent of HIV/AIDS among Inuit, and holding back of particular data all distort the relevant information (42). Another study by Hoffman-Goetz, seeking to ascertain the accuracy in portrayal by Aboriginal media of Aboriginal people's experiences with HIV/AIDS, found that Aboriginal women and youth were under-represented as sufferers from HIV/AIDS. Unlike mainstream media, in which the medical aspects of HIV/AIDS were dominant, the newspapers reviewed concentrated on Aboriginal culture, identity, spirituality and political-economic issues (54). Such media could link traditional and modern issues.

The media in both Hoffman-Goetz's studies $(42,54)$ accepted articles only in English, even though 70\% of Inuit people understand only Inuktitut (55). So, whilst the authors escaped the logistical challenges of translation, they might have excluded articles capable of influencing the Inuit. Also, the stories' impact may be lost in translation. The inclusion of the Nunatsiaq News improves the reliability of one study (42), since it contains anecdotal 'lived experience' Inuit bilingual articles. 


\section{Perceptions and Knowledge of HIV/AIDS}

Aboriginal awareness of HIV/AIDS issues remains far less than other Canadian populations. Aboriginal women's perceptions of HIV risk shows their misinformation concerning HIV-related risk behaviours (56). According to the Aboriginal AIDS Network, many Inuit believe "isolation from southern Canada will protect them from HIV/AIDS". Some believe that sharing needles in drug use is the only risk behaviour for HIV/AIDS (37), whilst others associate the risk with homosexuals (42).

"I guess like many kids I just thought it [HIV] was something that happened to homosexuals and drug users, so I never really thought about protected sex."

The statement above demonstrates how complacent is Aboriginal youth towards HIV, but shows they acknowledge the existence of high-risk groups (42). Surprisingly, some Aboriginal women felt there was a purpose for their infection with HIV - they deserved it, or it was, "part of the creator's plan for them" (38). The perceptions, knowledge and actions of those in contact with Inuit can influence their beliefs and behaviour. Two studies highlight the importance of Canadian pharmacist and nurse perspectives regarding HIV/AIDS, in Inuit willingness to participate in intervention activities (57, 58). Sontag eloquently explores many other ways in which global HIV/AIDS issues are portrayed and perceived in her book (59). Attention should focus on understanding local knowledge about HIV and sexual transmission in order to overcome the misconceptions that currently prevent behaviour change.

\section{Stigma, Discrimination, Fear and Stereotypes}

Stigma and discrimination prevent people from being tested, prevent condom use, affect breastfeeding behaviour and prevent marginalized groups such as IVDU from accessing care $(7,60-64)$. Lack of privacy and confidentiality in small communities can affect decisions to undergo testing and prevention attendance. Women tested for HIV experienced stigma and discrimination after test results were disseminated in their communities against their wishes (38). Stigma and discrimination may also turn HIV/AIDS into a taboo subject (65).

"Drug addicts don't even want to talk about it [AIDS] because of the fear. I talk to people and they tune out."

Sontag points out that global responses to AIDS identify and blame certain groups for its spread, in a similar way to past epidemics (59). Weaver provides an example of how Aboriginal stereotypes can affect policy decisions and perceptions of HIV/AIDS risk factors (66). Such stereotyping can delay HIV diagnosis and treatment, worsening immunological damage and increasing transmission risk. Early reliable testing is crucial.

\section{Health Beliefs and Health Seeking Behaviour}

Perceptions and knowledge influence health beliefs and therefore health behaviour. The definition of health according to the Canadian Health Care Act incorporates physical and mental wellbeing only (67). The World Health Organisation includes social well-being as an additional factor (68). However, both neglect spiritual well-being, which is important among Aboriginals. Health, according to Inuit traditional beliefs, results when an individual balances spirit, self and environment. The Aboriginal Nurses Association also mentions spiritual well-being in its definition (69). Inuit elders are an important source of information on the health practices of their past (70). One book records the elders' history and traditions, in which deep cuts were simply tied with cloth and lemming skins were used to treat boils, and describes birth before the Qallunaat (white person). Importantly, it portrays their own ability to take care of the sick (71). Modern evacuations of patients to distant hospitals disrupt families and communities, lessening a desire to seek treatment through fear of evacuation (38). Only one source analyzes Inuit health behaviour (72). Steenbeek proposed that because of their lower socioeconomic status, the Inuit have less future ambition, discouraging motivation to change health behaviour. Empowering health professionals should ensure that health services are applied with dignity and cultural sensitivity (72).

\section{Risk Factors for HIV Infection Among Inuit}

Sexual behaviour. High levels of sexual promiscuity among Inuit leave them susceptible to STI and therefore HIV transmission. Unprotected sex is a common HIV transmission method among Aboriginal peoples. Weaver suggests that high rates of STIs, implying a high frequency of sexual risk behaviours, can be used to estimate the frequency of the latter (66). Condom use is another important indicator of sexual risk behaviour.

Substance abuse. Inuit have a high alcohol intake (18), which is associated with increased risk of HIV transmission (73). High substance use and IVDU levels among Inuit also increases the risk of transmission, via the sharing of infected needles (46).

Crime. High crime rates and scarce correctional facilities in Nunavut mean that Aboriginals, including Inuit, are overrepresented in national prisons. The Canadian prisons' role in increasing Aboriginal risk of HIV infection was proposed by Lachmann's suggestion that Inuit people sent to distant urban prisons become stigmatised and involved in drug abuse (74). The high HIV prevalence and IVDU rates in prison point towards a possible AIDS epidemic. 
Other social and cultural problems. Following contact with early European explorers, Canadian Inuit entered a prolonged period of colonialisation and exploitation. Christianity spread by missionaries, replaced traditional shamanistic beliefs (18). Modernisation and disruption of traditional lifestyles, accompanied by occasional relocation of entire communities, led to significant deterioration in Inuit health. They now feel under-represented, lacking access to power and jobs, with low literacy rates and low educational attainment. They live in poor crowded housing, in remote and economically depressed communities with high levels of sickness and disease (19). These involuntary socio-economic factors create a predisposition to HIV infection $(46,75)$. High rates of domestic violence and sexual abuse leave Inuit women at greater risk. Frequent migration of individuals between communities or between rural and urban centres may facilitate the acquisition and spread of HIV infection. Many Inuit frequently travel locally and also between Northern and Southern Canada (76).

\section{Global HIV Prevention Strategies}

The main aim of HIV prevention is to put a stop to HIV transmission. It is estimated that $75 \%-85 \%$ of cases of HIV infections worldwide occur during sexual activity (77). Comprehensive, tailored preventions could avert the 45 million new cases expected this decade (6).

Prevention strategies depend on the duel efforts of:

1. Care and support for those living with HIV/AIDS

2. Targeted prevention for all people at risk or vulnerable to infection

The WHO stated in 2004 that global prevention programmes are inadequate, reaching only 1 in 5 people at risk (7). Many preventative methods are available, varying in costeffectiveness and benefits gained (78). Some key elements identified by the WHO for comprehensive HIV prevention (7) are shown in Table II.

Points 1-3 of Table II are evaluated below, accompanied by elements not included by WHO e.g. Male Circumcision (MC) and Needle Exchange Programs (NEPs). Other points although equally important, are covered in less detail in this review.

\section{Preventing and Treating STIs}

STIs and HIV share similar modes of transmission, prevention measures and target audiences. Biological mechanisms exist through which STIs facilitate HIV transmission by increasing HIV infectiousness and susceptibility (6). Detection and treatment of people with STIs are integral to HIV control. Clinical services offering STI prevention should be used simultaneously for offering HIV prevention, via HIV testing (6). A cohort study among
Table II. A list of key measures for the prevention of HIV/AIDS.

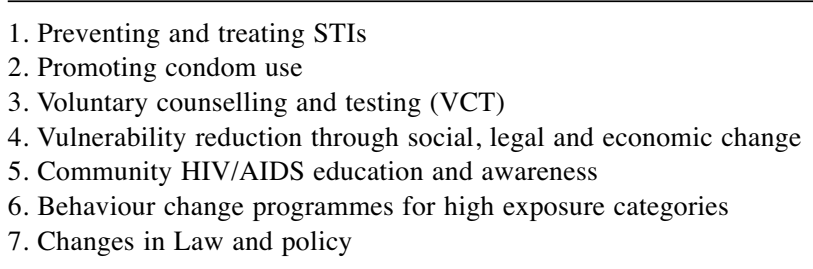

Australian Aboriginals has identified adaptable objective predictors of incident STIs, which can be used to target interventions and maximize their impact (79). Steenbeek utilises a holistic approach towards the prevention of STIs. She argues that since sexual health is linked to empowerment and equality between the sexes, nurses need to develop strategies to increase self-esteem, self advocacy and healthy choices among Aboriginal adolescents (72). Condoms remain the principal technological means of preventing sexual transmission of STIs and HIV, despite possibilities for their failure.

\section{Promoting Condom Use}

Observational studies confirm similar sexual behaviour patterns among Aboriginal, circumpolar and Inuit communities, including sexual activity with many partners among the young and infrequent condom use (18). Aboriginal teenagers are less likely to use condoms than non-Aboriginals (66). Using logical regression methods, another study concluded that Aboriginals most likely to use condoms were: below the age of 30, without a long-term sex partner, with more than one partner, worried about pregnancy, knowledgeable about HIV/AIDS, and not embarrassed to obtain condoms. Condom use increased among users if they had knowledge about HIV/AIDS or knew someone with HIV/AIDS. The belief that condom use was unnecessary among those with a steady sexual partner was the commonest reason against condom use (80). Brassard argues that gender roles affect use in native communities (81). Cole's survey found higher condom use during first-time intercourse among Nunavut youth, compared to the national average. However the results represent only a small pocket of Baffin Island's mixed youth (22). Dental Dams, acting as a barrier during oral sex, have been recommended for use by the Inuit (40). Their frequency of use has yet to be assessed.

\section{Male Circumcision (MC)}

Globally, $70 \%$ of HIV-positive men have acquired the virus through vaginal sex (77). Many studies show benefits for HIV prevention among men via male circumcision (MC), involving 
removal of the Langerhans' mucosa in the foreskin $(77,82-$ 85). A randomised trial, controlled for confounders such as behaviour, showed a causal association between HIV infection and MC, with the latter offering around $60 \%$ protection (83), consistent with other studies. Two reviews concluded that MC offers protection against other sexually transmitted infections including gonorrhoea $(77,82)$. Roles for neonatal circumcision and circumcision during puberty in the future/long-term prevention of HIV were mentioned. Most evidence supporting MC for HIV prevention is from observational studies in South/East African areas of higher HIV prevalence. The benefits could be partly explained by confounding, which was not adjusted for in the majority of cases, but this is unlikely. However, only the short-term benefits have been shown, leaving long-term effects and impact unknown.

\section{Needle Exchange Programmes (NEPs)}

An increase in IVDU is well-documented in over 80 countries. When IVDU emerges, the accompanying health consequences, including HIV, typically follow. Many HIV prevention strategies targeting IVDU have been effective in developed and developing countries, including peer education, social network interventions and needle exchange programs (NEPs) (86). One study questioned the effectiveness of NEPs in an urban context, showing higher infection rates among frequent NEP users, which suggests that needle exchange programmes exacerbate HIV spread (87). The mechanism proposed is via aiding the formation of high-risk social networks. Another study found no evidence to suggest that NEPs are causally associated with HIV transmission and that formation of such networks is minimal (88). However, the main benefit remains clear - that NEPs can attract high risk IVDU and therefore provide a window of opportunity to access otherwise difficult-to-reach individuals. Canadian law stipulates that it is illegal to sell, exchange or provide a syringe to an IVDU, but no laws exist requiring a physician's prescription to justify possession of a syringe. Such loopholes identify weaknesses in Canadian law, further worsening the spread of infection (89).

\section{Voluntary Counselling and Testing (VCT)}

Globally, the current reach of HIV testing is poor, with only 1 in 10 pregnant women offered services for preventing mother-to-child transmission (MTCT) (7). MTCT is responsible for $90 \%$ of infections among children, whilst the remaining $10 \%$ are infected by contaminated blood or sexual abuse (90). Testing is the only way to confirm the possible existence of Harrison's proposed 'iceberg of disease'. Guidelines suggest that a prevalence of $1 \%$ is the general threshold for recommending routine screening (91). Knowledge of HIV status is the most powerful encouragement for behaviour change (92). Voluntary counselling and testing (VCT) is a combination of two activities - counselling and testing- representing the gateway to HIV treatment and prevention. It is successfully used for early identification of HIV, forming a universal and routine part of Canadian medical care, which offers counselling before and after testing, for both positive and negative patients. Nationally, $0.3 \%-0.4 \%$ of people undergoing VCT were HIV-positive. MTCT prevention services screened $60 \%-98 \%$ of women in 2002 and $1.9 \%$ of babies born to HIV-positive mothers were confirmed HIV positive (27).

Low-uptake remains the problem. In Nunavut, geography and isolation limits testing availability, whilst fear of associated stigma and discrimination discourage use of VCT (7). Wardman's survey found that many Aboriginals preferred accessing health services provided by an Aboriginal (93). Uptake of services differs between risk groups, for example IVDU (94). In Africa, social marketing is used to promote interventions such as VCT, but limited Arctic resources limit its applicability. Self-testing is a recent alternative option for those unwilling or unable to access VCT services. It is used in developing countries, offering greater privacy and convenience, with results in $20 \mathrm{~min}$ (92). There are very few emotional support opportunities for a geographically isolated HIV-positive Inuit person, experiencing fear, shock and isolation. The Internet might bring people together and provide strong support groups for those distant and in-need and improve Inuit mental health. Email contact between doctors and patients has been tried in Greenland.

\section{Discussion}

Ideally this review would include other dimensions such as cost-effectiveness, but could not do so, owing to the paucity of Inuit-specific HIV/AIDS research. Including information from other countries was, therefore, necessary. Since most Canadian-Inuit research is presented within an Aboriginal context, it is difficult to know whether the interpretations represent the Inuit minority. Despite these limitations, which support the need for Inuit-specific research, this review provides a range of evidence covering relevant issues.

Issues identified in the evidence regarding the central questions outlined in the introduction, are discussed below. The most important problem to be addressed is the Inuit lack of awareness and understanding HIV. Global and Aboriginal women, IVDUs and Youth remain at increased risk. The Inuit are unaware of the non-discriminatory risk of HIV infection. Research is required to investigate whether other risk groups exist and the role of proposed risk behaviours. The evidence suggests many factors increase Inuit acquisition of HIV. Most involve voluntary behaviour but economic factors also have a role. Inuit-perceived roles of 
sexual behaviour, substance abuse and socio-cultural factors remain unknown and need further research. High STI rates suggest the need to investigate sexual transmission. Effective interventions to lower STI transmission would lower the risk posed by HIV. Transmission via IVDU highlights national policy weaknesses, particularly within prisons. The sociocultural factors influencing risk need further investigation.

Isolation from Southern Canada and homosexuals distorts Inuit perceptions of HIV risk. Local media, as accessible and influential sources of information, should exercise a more accurate educational responsibility, that would reduce Inuit misconceptions and develop their understanding of HIV. Reassessment of the roles and responsibilities of Inuit sources of health information, such as the media, health care providers, elders and traditional healers is needed.

The Inuit population is in clear need of successful STI interventions. However, the Nunavut population is not entirely Inuit, so care has to be taken whilst addressing Inuit needs, since another minority with different needs could be neglected. Effective prevention programs aimed at sexual transmission offer dual benefits to the Inuit by controlling high STIs rates and preventing HIV. The current detection and treatment services for STI patients, HIV testing, surveillance and treatment could be offered to the same target audience.

Condoms remain the most effective prevention method, being applicable anywhere. Wide condom availability in Canada does not guarantee Inuit access to them or ensure their quality or correct use. Condom use largely depends upon personal choice, which in turn is influenced by traditional and social factors. Culturally appropriate social marketing strategies are needed to reiterate their importance in STI/HIV prevention. Research into condom use should be put into context always, using national averages. There is no research on the effectiveness of dental dams in prevention.

MC and NEPs have shown benefits in reducing transmission and further use should be researched. MC is a potential population-level intervention, as demonstrated in areas of high prevalence. Neonatal MC only provides future prevention and offers no short-term benefits. Whilst most prevention programs covered are those that prevent sexual transmission of HIV, NEPs offer the prevention of shared needle use. The benefits of the syringe exchange programs in Canada are evident, but are currently insufficient to control the HIV rise among IVDUs.

Evidence suggests that current approaches to screening are inadequate. Then HIV data capture only those who are tested, whose HIV infection is diagnosed and whose positive test results are reported to Health Canada. HIV testing is easily declined by the Inuit population in Nunavut where it is offered. Therefore caution has to be taken when reviewing data, as the numbers stated do not represent the total number of Aboriginals infected with HIV or those whose AIDS has been diagnosed. VCT could be used to confirm the existence of an 'HIV iceberg'. VCT consent rates remain low among Inuit owing to perceived poor provider-patient relationships and lack of understanding. In addition, many Inuit fear HIV testing, because of confidentiality issues and the necessity to travel for treatment. HIV status would change health behaviour and improve understanding among other Inuit. People have the right to know whether they are infected with HIV, and have help in understanding the implications. Few Inuit communities are prepared to care for an Inuit with HIV/AIDS and neither is the Nunavut health care system wellprepared. Counselling would improve Inuit mental health and patient-provider relationships. However, there is a staff shortage, limiting the feasibility of DOT programs. MTCT provides many benefits and culturally-sensitive material in Inuktitut should be available, clearly stating the benefits of testing, accompanied by informed encouragement. No national data exist to substantiate claims that all health services that should offer VCT, do offer it, there is no operational strategy for identifying barriers to VCT and no plans for anti-retroviral therapy (ART), VCT or MTCT prevention strategy training.

Self-testing could serve those Inuit who do not have access to testing services or who do not use standard facilitybased services because of concerns over privacy, stigma, transport costs, or other barriers. The main problem in selftesting among the Inuit is that there is no encouragement or advice to seek further help. Its impact on risk behaviours, its effective use among untrained people or those at risk and its safety and cost-effectiveness remain unknown since its inception in 2004. Other testing methods including home specimen collection are simply not feasible in the Arctic.

Western medicine emphasizes on disease treatment, but traditional medicine emphasizes on disease prevention. The absence of social and spiritual well-being components in Canadian health policy highlights the current disregard for traditional beliefs. Tradition still remains at the core of Inuit health. Traditional health behaviours reduce recommended treatment uptake and adherence, creating a treatment barrier. Combining modern and traditional medicine could improve patient-provider relationships. Alternative access methods, such as using traditional healers, might improve adherence to treatment, in turn reducing resistance.

Resistance is a permanent threat for patients who are undergoing ART. However since resistant HIV can be spread, it remains a threat for the rest of the population. Therefore HIV prevention should be accompanied by resistance prevention, including unrelenting patient education regarding resistance and the importance of treatment adherence to ensure efficacy. More research is needed on ART side-effects among Inuit populations. The guaranteed local availability of supportive treatments such as anti-diarrhoeal drugs, to prevent these effects impinging on Inuit lifestyle, would also help improve adherence. Although ART is being used under 
accepted guidelines, there are no criteria for determining ART needs. Regular monitoring of patients' therapeutic responses is important. Since not every community has its own health centre, the only other option is to keep the patient in hospital for the entire period. This would prove costly and detrimental to their mental health.

It is important to retain a population-specific, flexible nonjudgemental approach in evaluating adherence since treatment failure is not always because of adherence problems. Identifying patients more at risk of non-adherence is difficult but does help. However, care should be taken not to discriminate against drug users, since adherence is not a problem for all of them. Steps to maximise adherence in all patients should be reviewed. Many strategies can be used, particularly education.

Literature regarding ART access issues among Aboriginals and therefore Inuit in Canada is sparse. It is of particular concern that Aboriginals have the slowest uptake, but that as a subgroup, IVDUs are more at risk. Service delivery could be improved by relying on decentralised services and community health representatives. However local visits by nurses and deliveries of drugs to patients do occur in smaller Inuit communities where unchallenged misunderstanding can lead to HIV-related stigma, diminishing treatment access and uptake.

\section{Conclusion and Future Perspectives}

The Inuit have faced significant challenges in the past century. The impact of modernisation has led to a consequential health transition. HIV/AIDS, a nondiscriminatory disease, remains a potential public health catastrophe among Inuit, with current high rates of STI transmission demonstrating their vulnerability. Education is the single-most effective prevention, building upon the existing health knowledge of Inuit and encouraging acknowledgement of the threat. An updated and culturally relevant sex-education curriculum is needed. There is an absence of Inuit-specific HIV/AIDS-related research into traditions, understanding, perceptions, knowledge, attitudes and behaviour. Research must acknowledge and appreciate the differences between the Inuit and other Aboriginal groups. The inclusion of ethnicity is important. Acknowledgment and protection of their traditional way of life would improve their well-being and develop better provider-patient relationships, ensuring their survival. Any initiative, strategy, programme or information must be provided in an appropriate and accessible format and implemented via community-based health care in order to be effective. Recommendations for the design and development of more effective prevention materials are shown in Table III.

HIV/AIDS understanding, prevention and treatment are complex problems that exceed the capability of any one
Table III. A list of key measures for the design and development on future strategies for the surveillance and prevention of HIV/AIDS in Inuit.

1. Inuit-specific

2. Culture-sensitive

3 . With language translation

4. Targets appropriate high risk groups

5 . Routinely evaluated

6. Financial and government support for those showing benefits

7. Promote empowerment, ownership and awareness

8. Inuit organisation and local/elders advisory input and feedback

sector. Evidence suggests more can be done to prevent a further deterioration in Inuit health. Appropriate HIV prevention and treatment strategies need to be devised, to meet complex Inuit health needs. This review provides a foundation and justification for further qualitative research on the Canadian Inuit understanding of HIV/AIDS in the context of the main aim to help prevent HIV infection among Inuit.

\section{Acknowledgements}

The Author gratefully acknowledges awards of travel bursaries from The Lancet, AstraZeneca and King's College (London). Some of the data have been presented as a poster (International HIV Conference, Toronto, Canada) and an oral communication (International Circumpolar Conference, Norway). The details of the work can be found in a dissertation submitted to the Leeds University (200234082). This work has been a subject of media coverage and some of the recommendations have been implemented.

\section{References}

1 Graziani GM and Angel JB: Hiv-1 immunogen: An overview of almost 30 years of clinical testing of a candidate therapeutic vaccine. Expert Opin Biol Ther 16(7): 953-966, 2016.

2 Javalkar P, Prakash R, Isac S, Washington R and Halli SS: An estimation of mortality risks among people living with hiv in karnataka state, india: Learnings from an intensive hiv/aids care and support programme. PLoS One 11(6): e0156611, 2016.

3 O'Brien KK, Tynan A-M, Nixon SA and Glazier RH: Effectiveness of aerobic exercise for adults living with hiv: Systematic review and meta-analysis using the cochrane collaboration protocol. BMC Infect Dis 16(1): 182, 2016.

4 Poorolajal J, Hooshmand E, Mahjub H, Esmailnasab N and Jenabi E: Survival rate of aids disease and mortality in hivinfected patients: A meta-analysis. Public Health, 2016.

5 HIV/AIDS: A fact sheet. National Aboriginal Health Orgnization, April 2009.

6 Organisation UNAWH: Epidemiological fact sheets on hiv/ stis, 2004 update. 2004

7 UNAIDS: Report on the global aids epidemic: Executive summary. Geneva: World Health Organisation, 2004. 
8 Shea B, Aspin C, Ward J, Archibald C, Dickson N, McDonald A, Penehira M, Halverson J, Masching R and McAllister S: Hiv diagnoses in indigenous peoples: Comparison of australia, canada and new zealand. International Health 3(3): 193-198, 2011.

9 Adetokunboh $\mathrm{OO}$ and Oluwasanu M: Eliminating mother-tochild transmission of the human immunodeficiency virus in subsaharan africa: The journey so far and what remains to be done. J Infect Public Health 9(4): 396-407, 2016.

10 Nunavut government. Our land. Iqaluit.

11 Szathmary E: Mtdna and the peopling of the americas. Am J Hum Genet 53(4): 793, 1993

12 Improving the health of canadians: Aboriginal peoples' health. Chapter 4. Ottawa: Canadian Institute for Health Information, 2004.

13 Kanatami IT: Backgrounder on inuit health. Health Sectoral meeting Ottawa, Ontario, 2004

14 Quinn TC, Wawer MJ, Sewankambo N, Serwadda D, Li C, Wabwire-Mangen F, Meehan MO, Lutalo T and Gray RH: Viral load and heterosexual transmission of human immunodeficiency virus type 1. N Engl J Med 342(13): 921-929, 2000.

15 Canada. PHAO: Summary: Estimates of hiv incidence, prevalence and proportion undiagnosed in canada, 2014. Public Health Agency of Canada, 2015.

16 de Lima ICV, Galvão MTG, de Oliveira Alexandre H, Lima FET and de Araújo TL: Information and communication technologies for adherence to antiretroviral treatment in adults with hiv/aids. Int J Med Inform 92: 54-61, 2016.

17 Kalapila AG and Marrazzo J: Antiretroviral therapy for prevention of human immunodeficiency virus infection. Med Clin North Am 100(4): 927-950, 2016.

18 Cruikshank J: The circumpolar inuit: Health of a population in transition. Peter bjerregaard and t. Kue young. 1998 Copenhagen: Munksgaard. Polar Record 35(195): 355-357, 1999.

19 Bjerregaard P, Young TK, Dewailly E and Ebbesson SO: Indigenous health in the arctic: An overview of the circumpolar inuit population. Scandinavian Journal of Public Health 32(5): 390-395, 2004.

20 Hogg RS, Heath K, Lima VD, Nosyk B, Kanters S, Wood E, Kerr T and Montaner JS: Disparities in the burden of hiv/aids in canada. PLoS One 7(11): e47260, 2012.

21 Canada H: Hiv/aids among aboriginal peoples in canada: A continuing concern. Hiv/ aids epi update. Ottawa: Public health agency of Canada, 2004

22 Cole M: Youth sexual health in nunavut: A needs based survey of knowledge, attitudes and behaviour. Int J Circumpolar Health 63: 270-273, 2004

23 Fleming DT and Wasserheit JN: From epidemiological synergy to public health policy and practice: The contribution of other sexually transmitted diseases to sexual transmission of hiv infection. Sex Transm Infect 75(1): 3-17, 1999.

24 Bogach V and Trotsenko O: The development of hiv infection in the far-eastern region of the russian federation. Zhurnal mikrobiologii, epidemiologii, i immunobiologii 1: 13-16, 1998.

25 Nunavut government. Comparable health indicators for nunavut and canada. Iqaluit: Nunavut Department of Health and Social Services: 1-44, 2002.

26 Shephard RJ and Rode A: The health consequences of 'modernisation': Evidence from circumpolar peoples. Cambridge University Press, 1996.
27 Fact sheets on hiv/aids care and treatment canada. 2004 october update. United Nations AIDS/ World Health Organisation, 2004.

28 Public health agency of canada. Hiv and aids in canada: Surveillance report to june 30, 2004. In: Health Canada, ed Ottawa: Surveillance and Risk Assessment Division, 2004.

29 HA A: The canadian health care system. Edmonton: University of Alberta, 1995

30 Ferry J: How will the health of the inuit fare in their new land? The Lancet 354(9175): 312, 1999.

31 Canada $\mathrm{H}$ : Branches, regions and agencies.

32 Rana Z BM, Wilson K, Cohen JC: Access to essential medicines and the canadian aboriginal population: Core features of the drug program and policy issues. Comparative program on health and society. Toronto: University of Toronto, 2004.

33 Edwards K, Mitchell S, Gibson NL, Martin J and Zoe-Martin C: Community-coordinated research as hiv/aids prevention strategy in northern canadian communities. Pimatisiwin 6(2): 111-127, 2008.

34 Walker N, Garcia-Calleja JM, Heaton L, Asamoah-Odei E, Poumerol G, Lazzari S, Ghys PD, Schwartländer B and Stanecki KA: Epidemiological analysis of the quality of hiv serosurveillance in the world: How well do we track the epidemic? AIDS 15(12): 1545-1554, 2001.

35 Garmaise D: Commons committee recommends significant increase in funding for aids strategy. Canadian HIV/AIDS policy \& law review/Canadian HIV/AIDS Legal Network 8(2): 24-25, 2003.

36 Crown M, Duncan K, Hurrell M, Ootoova R, Tremblay R and Yazdanmehr S: Making hiv prevention work in the north. Canadian Journal of Public Health 84: S55-58, 1993.

37 (CIHAN) TCIHAN: Hiv/aids \& inuit. In: Network CAA, ed Ottawa,

38 Mill JE: Describing an explanatory model of hiv illness among aboriginal women. Holist Nurs Pract 15(1): 42-56, 2000.

39 Harrison D: Hiv epidemic in north disputed. Vancouver: The Province: A27, 2003.

40 Organisation niichr. Coping with HIV in Aboriginal Communities: A 1998 resource Manual, 1998.

41 Marzuk PM, Tierney H, Tardiff K, Gross EM, Morgan EB, Hsu M-A and Mann JJ: Increased risk of suicide in persons with aids. JAMA 259(9): 1333-1337, 1988.

42 Hoffman-Goetz L, Friedman DB and Clarke JN: Hiv/aids risk factors as portrayed in mass media targeting first nations, métis, and inuit peoples of canada. Journal of Health Communication 10(2): 145-162, 2005.

43 McKeown I, Reid S and Orr P: Experiences of sexual violence and relocation in the lives of hiv infected canadian women. Int J Circumpolar Health 63(Suppl. 2): 399-404, 2004.

44 Drake AL, Wagner A, Richardson B and John-Stewart G: Incident hiv during pregnancy and postpartum and risk of mother-to-child hiv transmission: A systematic review and metaanalysis. PLoS Med 11(2): e1001608, 2014.

45 Fouda GG, Moody MA and Permar SR: Antibodies for prevention of mother-to-child transmission of hiv-1. Curr Opin HIV AIDS 10(3): 177-182, 2015.

46 Reynolds GL, Fisher DG, Estrada AL and Trotter R: Unemployment, drug use, and hiv risk among american indian and alaska native drug users. American Indian Alaskan Native Mental Health Res 9(1): 17-32, 2000.

47 Kain T, Fowler S, Grennan T, A, Maxwell J, Wilton J and Tan DHS: Low perceptions of hiv risk among toronto msm seeking 
anonymous hiv testing: Objestive and subjctive assessments of prep eligibility. International Association of Providers of AIDS Care (IAPAC), controlling the HIV epidemic with antiretrovirals: Avoiding the cost of inaction, London, UK, 2013.

48 Grewal R, Allen VG, Gardner S, Moravan V, Tan DH, Raboud J, Bayoumi AM, Kaul R, Mazzulli T, McGee F, Rourke SB, Burchell AN and Team OCSR: Serosorting and recreational drug use are risk factors for diagnosis of genital infection with chlamydia and gonorrhoea among hiv-positive men who have sex with men: Results from a clinical cohort in ontario, canada. Sex Transm Infect, 2016.

49 Young TK and Katz A: Survivors of sexual abuse: Clinical, lifestyle and reproductive consequences. Can Med Assoc J 159(4): 329-334, 1998

50 Leonardi M, Lee E and Tan DH: Awareness of, usage of and willingness to use hiv pre-exposure prophylaxis among men in downtown toronto, canada. Int J STD AIDS 22(12): 738-741, 2011

51 Liu J, Remis RS, Loutfy M, Tharao W, Rebbapragada A, Halpenny R, ... and Kaul R: Prevalence and correlates of sexually transmitted co-infections in hiv-positive men who have sex with men in toronto. Poster session P105 presented at the meeting of Canadian Conferrence on HIV/AIDS Research (CAHR), St Jhon's, Newfoundland and Labrador, Canada, 2014, May 1-4.

52 Kesler MA, Kaul R, Liu J, Loutfy M, Gesink D, Myers T and Remis RS: Actual sexual risk and perceived risk of hiv acquisition among hiv-negative men who have sex with men in toronto, canada. BMC Public Health 16(1): 254-259, 2016.

53 Kesler MA, Kaul R, Myers T, Liu J, Loutfy M, Remis RS and Gesink D: Perceived hiv risk, actual sexual hiv risk and willingness to take pre-exposure prophylaxis among men who have sex with men in toronto, canada. AIDS Care: 1-8, 2016.

54 Clarke JN, Friedman DB and Hoffman-Goetz L: Canadian aboriginal people's experiences with hiv/aids as portrayed in selected english language aboriginal media (1996-2000). Soc Sci Med 60(10): 2169-2180, 2005.

55 Statistics canada. Inuit information from canadian 2001 census. 2003.

56 Morrison-Beedy D, Carey MP, Lewis BP and Aronowitz T: Hiv risk behavior and psychological correlates among native american women: An exploratory investigation. J Womens Health Gend Based Med 10(5): 487-494, 2001.

57 Armstrong-Esther $\mathrm{C}$ and Hewitt W: Knowledge and perception of aids among canadian nurses. J Adv Nurs 14(11): 923-938, 1989.

58 Myers T, Cockerill R, Worthington C, Millson M and Rankin J: Community pharmacist perspectives on hiv/aids and interventions for injection drug users in canada. AIDS Care 10(6): 689-700, 1998.

59 Sontag S: Illness as a metaphor, aids and its metaphors. Penguin Classics, 1993.

60 Garbin D and Millington G: Territorial stigma and the politics of resistance in a parisian banlieue: La courneuve and beyond. Urban studies 49(10): 2067-2083, 2012.

61 Chambers LA, Rueda S, Baker DN, Wilson MG, Deutsch R, Raeifar E, Rourke SB and Team S: Stigma, hiv and health: A qualitative synthesis. BMC Public Health 15(1): 848-854, 2015.

62 Collins AB, Parashar S, Closson K, Turje RB, Strike C and McNeil R: Navigating identity, territorial stigma, and hiv care services in vancouver, canada: A qualitative study. Health Place 40: 169-177, 2016.
63 Goldenberg SM, Brouwer KC, Jimenez TR, Miranda SM and Mindt MR: Enhancing the ethical conduct of hiv research with migrant sex workers: Human rights, policy, and social contextual influences. PLoS One 11(5): e0155048, 2016.

64 Graham LF, Padilla MB, Lopez WD, Stern AM, Peterson J and Keene DE: Spatial stigma and health in postindustrial detroit. Int Q Community Health Educ 36(2): 105-113, 2016.

65 Connors MM: The politics of marginalization: The appropriation of aids prevention messages among injection drug users. Cult Med Psychiatry 19(4): 425-452, 1995.

66 Weaver HN: Through indigenous eyes: Native americans and the hiv epidemic. Health Soc Work 24(1): 27-34, 1999.

67 Canadian legal information institute. Canadian primary health care policy and objective \#3., 1984.

68 WHO: Declaration of alma-ata. International conference on primary care 1978, alma-ata. World Health Organisation, 1978.

69 Aboriginal nurses association. Definition of health. Aboriginal nurses association of canada partnership guidelines. 1999.

70 Gray G: Health care in north must acknowledge inuit values, traditional medicine. Can Med Assoc J 155(11): 1613-1614, 1996.

71 Nakasuk S: Interviewing the elders: Introduction. 1 ed: Nunavut Arctic College, 1999.

72 Steenbeek A: Empowering health promotion a holistic approach in preventing sexually transmitted infections among first nations and inuit adolescents in canada. J Holist Nurs 22(3): 254-266, 2004.

73 Baldwin JA, Maxwell CJ, Fenaughty AM, Trotter RT and Stevens SJ: Alcohol as a risk factor for hiv transmission among american indian and alaska native drug users. American Indian and Alaska native mental health research (Online) 9(1): 1-16, 2000.

74 Lachmann M: Human immunodeficiency virus. Emerging epidemic in aboriginal people. Can Fam Physician 48: 15921593, 1600-1591, 2002.

75 Hargreaves JR, Morison LA, Chege J, Rutenburg N, Kahindo M, Weiss HA, Hayes R and Buvé A: Socioeconomic status and risk of hiv infection in an urban population in kenya. Trop Med Int Health 7(9): 793-802, 2002.

76 Tseng A: Anonymous hiv testing in the canadian aboriginal population. Can Fam Physician 42: 1734-1740, 1996.

77 Szabo R and Short RV: How does male circumcision protect against hiv infection? BMJ 320(7249): 1592-1594, 2000.

78 Anis A: Review: The cost-effectiveness of interventions for hiv/aids in africa varies greatly. Evidence Based Medicine $8(1)$ : 32-32, 2003.

79 Miller P, Law M, Torzillo P and Kaldor J: Incident sexually transmitted infections and their risk factors in an aboriginal community in australia: A population based cohort study. Sex Transm Infect 77(1): 21-25, 2001.

80 Calzavara L, Burchell A, Myers T, Bullock S, Escobar M and Cockerill R: Condom use among aboriginal people in ontario, canada. Int J STD AIDS 9(5): 272-279, 1998.

81 Brassard P, Smeja C and Valverde C: Needs assessment for an urban native hiv and aids prevention program. AIDS Educ Prev 8(4): 343-351, 1996.

82 De Vincenzi I and Mertens T: Male circumcision: A role in hiv prevention? AIDS 8(2): 153-160, 1994.

83 Auvert B, Taljaard D, Lagarde E, Sobngwi-Tambekou J, Sitta R and Puren A: Randomized, controlled intervention trial of male circumcision for reduction of hiv infection risk: The anrs 1265 trial. PLoS Med 2(11): e298, 2005. 
84 Siegfried N, Muller M, Deeks J, Volmink J, Egger M, Low N, Walker $\mathrm{S}$ and Williamson P: Hiv and male circumcision-a systematic review with assessment of the quality of studies. The Lancet Infectious Diseases 5(3): 165-173, 2005.

85 Gray RH, Kigozi G, Serwadda D, Makumbi F, Watya S, Nalugoda F, Kiwanuka N, Moulton LH, Chaudhary MA, Chen MZ, Sewankambo NK, Wabwire-Mangen F, Bacon MC, Williams CF, Opendi P, Reynolds SJ, Laeyendecker O, Quinn TC and Wawer MJ: Male circumcision for hiv prevention in men in rakai, uganda: A randomised trial. Lancet 369(9562): 657-666, 2007.

86 Ball AL, Rana S and Dehne KL: Hiv prevention among injecting drug users: Responses in developing and transitional countries. Public Health Rep 113(Suppl 1): 170-179, 1998.

87 Bruneau J, Lamothe F, Franco E, Lachance N, Désy M, Soto J and Vincelette $\mathrm{J}$ : High rates of hiv infection among injection drug users participating in needle exchange programs in montreal: Results of a cohort study. Am J Epidemiol 146(12): 994-1002, 1997.

88 Schechter MT, Strathdee SA, Cornelisse PG, Currie S, Patrick DM and Rekart ML: Do needle exchange programmes increase the spread of hiv among injection drug users?: An investigation of the vancouver outbreak. AIDS 13(6): F45-F51, 1999.

89 Hankins CA: Syringe exchange in canada: Good but not enough to stem the hiv tide. Subst Use Misuse 33(5): 1129-1146, 1998.
90 Petitet PH: Anthropological perspectives on hiv/aids transmission during delivery. AIDS and Maternity in India From Public Health to Social Sciences Perspectives Emerging themes and Debates: 211-224, 2004.

91 Sanders GD, Bayoumi AM, Sundaram V, Bilir SP, Neukermans CP, Rydzak CE, Douglass LR, Lazzeroni LC, Holodniy M and Owens DK: Cost-effectiveness of screening for hiv in the era of highly active antiretroviral therapy. N Engl J Med 352(6): 570585, 2005.

92 Spielberg F, Levine RO and Weaver M: Self-testing for hiv: A new option for hiv prevention? The Lancet Infectious Diseases 4(10): 640-646, 2004.

93 Wardman D, Clement K and Quantz D: Access and utilization of health services by british columbia's rural aboriginal population. Leadersh Health Serv 18(2): 26-31, 2005.

94 Wood E, Kerr T, Palepu A, Zhang R, Strathdee SA, Tyndall MW, Montaner JS and Hogg RS: Slower uptake of hiv antiretroviral therapy among aboriginal injection drug users. J Infect 52(4): 233-236, 2006
Received September 30, 2015

Revised July 20, 2016

Accepted July 21, 2016 